OECD Environmental Health and Safety Publications

Series on Testing and Assessment

No. 7

\title{
GUIDANCE DOCUMENT ON DIRECT PHOTOTRANSFORMATION OF CHEMICALS IN WATER
}

\author{
Environment Directorate \\ Organisation For Economic Co-operation And Development
}

Paris 1997 
Also published in the Series on Testing and Assessment:

No. 1, Guidance Document for the Development of OECD Guidelines for Testing of Chemicals (1993; reformatted 1995)

No. 2, Detailed Review Paper on Biodegradability Testing (1995)

No. 3, Guidance Document for Aquatic Effects Assessment (1995)

No. 4, Report of the OECD Workshop on Environmental Hazard/Risk Assessment (1995)

No. 5, Report of the SETAC/OECD Workshop on Avian Toxicity Testing (1996)

No. 6, Report of the Final Ring Test of the Daphnia magna Reproduction Test

Ring Test of the Comparison of Ecological Hazard/Risk Assessment Schemes (in preparation)

Guidance Document on Dose Level Selection in Carcinogenicity Studies (in preparation)

Detailed Review Paper on Aquatic Toxicity Testing Methods (in preparation) made to: Head of Publications Service, OECD, 2 rue André-Pascal, 75775 Paris Cedex 16, France. 


\begin{abstract}
About the OECD
The Organisation for Economic Co-operation and Development (OECD) is an intergovernmental organisation in which representatives of 29 industrialised countries in North America, Europe and the Pacific, as well as the European Commission, meet to co-ordinate and harmonize policies, discuss issues of mutual concern, and work together to respond to international problems. Most of the OECD's work is carried out by more than 200 specialized Committees and subsidiary groups composed of Member country delegates. Observers from several countries with special status at the OECD, and from interested international organisations, attend many of the OECD's Workshops and other meetings. Committees and subsidiary groups are served by the OECD Secretariat, located in Paris, France, which is organised into Directorates and Divisions.

The work of the OECD related to chemical safety is carried out in the Environmental Health and Safety Programme. As part of its work on chemical testing, the OECD has issued several Council Decisions and Recommendations (the former legally binding on Member countries), as well as numerous Guidance Documents and technical reports. The best known of these publications, the OECD Test Guidelines, are a collection of methods used to assess the hazards of chemicals and of chemical preparations such as pesticides and pharmaceuticals. They cover tests for physical and chemical properties, effects on human health and wildlife, and accumulation and degradation in the environment. The OECD Test Guidelines are recognised worldwide as the standard reference tool for chemical testing.

More information about the Environmental Health and Safety Programme and its publications is available on the OECD's World Wide Web site (see page 6).

The Environmental Health and Safety Programme co-operates closely with other international organisations. This document was produced within the framework of the Inter-Organization Programme for the Sound Management of Chemicals (IOMC).
\end{abstract}


This publication is available electronically, at no charge.

For the complete text of this and many other Environmental Health and Safety publications, consult the OECD's World Wide Web site (http://www.oecd.org/ehs/)

or contact:

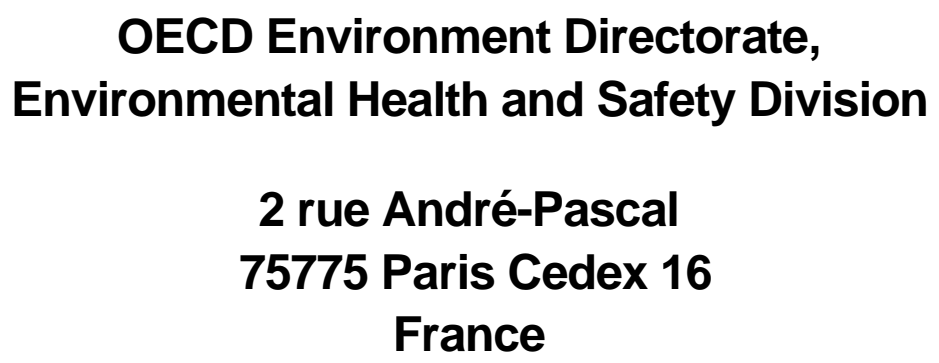

Fax: (33-1) 45241675

E-mail: ehscont@oecd.org

The Inter-Organization Programme for the Sound Management of Chemicals (IOMC) was established in 1995 by UNEP, ILO, FAO, WHO, UNIDO and the OECD (the Participating Organizations), following recommendations made by the 1992 UN Conference on Environment and Development to strengthen co-operation and increase international co-ordination in the field of chemical safety. The purpose of the IOMC is to promote co-ordination of the policies and activities pursued by the Participating Organizations, jointly or separately, to achieve the sound management of chemicals in relation to human health and the environment. 


\section{FOREWORD}

Rather recently, the OECD Secretariat received almost simultaneously three proposals for an OECD Test Guideline on Direct Phototransformation in Water, i.e. aqueous photolysis. The purpose of this Guidance Document is to situate these proposals in a broad context consisting of the basic concepts of photochemistry applicable to aqueous photolysis, the existing national guidelines and standards, and the results of a ring test held under the aegis of ECETOC.

In respect of basic concepts, this document is a brief introduction and should not be considered a comprehensive overview of the science and techniques that are applicable to the investigation and evaluation of the transformations chemicals may undergo when exposed to light in the water compartment. Formulas, equations and units used in photochemistry tend to be complicated. They have been reduced here to the strict minimum, and those given may even be approximate. For better insight the reader may want to consult the book by Asa Leifer, The Kinetics of Environmental Aquatic Photochemistry Theory and Practice, (ACS Professional Reference Book, American Chemical Society, 1988). As such, the Guidance Document may nevertheless be useful to officials in Member countries who are responsible for notifications and hazard assessment and who may not be fully familiar with photochemistry.

Existing national guidelines and standards referred to are only summarised and referenced. Most of them were circulated to Member countries as annexes to a previous draft of this document. All other pieces of important background information are also only summarised and/or referenced.

This Guidance Document, although it was triggered by the submission of three different proposals, is not at all to be considered as an embryonic Test Guideline. Rather, it may provide a good basis for the already scheduled concerted action on a new OECD Test Guideline on this subject.

The Joint Meeting of the Chemical Group and Management Committee of the Special Programme on the Control of Chemicals recommended that this document be made public. It is being published on the responsibility of the Secretary-General of the OECD. 


\section{TABLE OF CONTENTS}

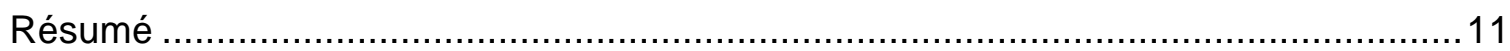

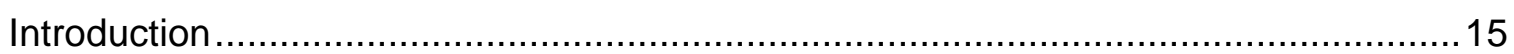

Part 1 Photochemical processes in the aquatic environment and methods for estimating and measuring photochemical transformation..................17

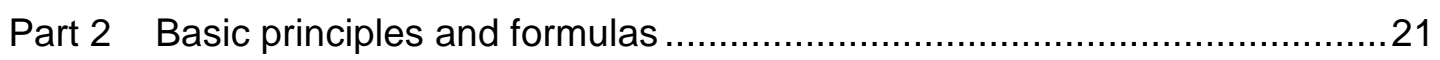

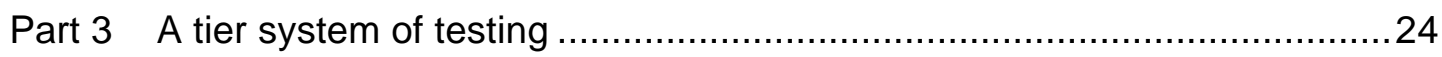

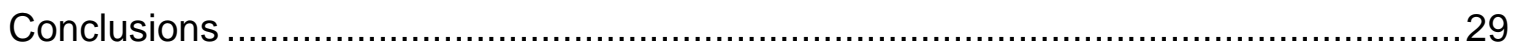

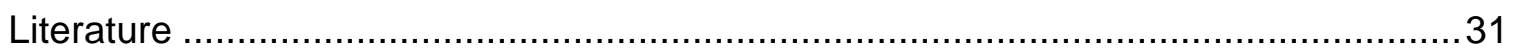

Annex

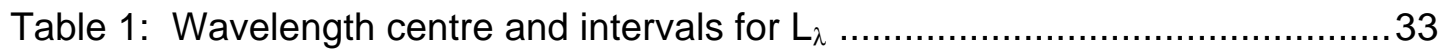

Table 2: $L_{\lambda}$ values for latitude $20^{\circ} \mathrm{N}$ (North America) ........................................ 34

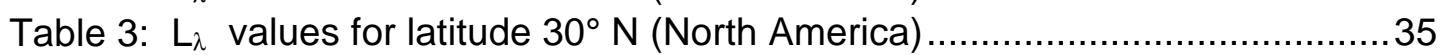

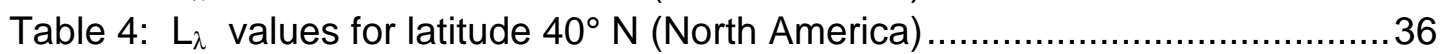

Table 5: $L_{\lambda}$ values for latitude $50^{\circ} \mathrm{N}$ (North America) .........................................37 


\section{RESUME}

Le Secrétariat de l'OCDE a reçu à courts intervalles trois propositions différentes pour une Ligne Directrice sur la phototransformation directe (photolyse) en milieu aquatique. II y avait deux propositions officielles, l'une en 1992 émanant du Umweltbundesamt allemand (1) et l'autre émanant du Department of the Environment du Royaume-Uni (2). En outre, en 1992, le Secrétariat eut connaissance d'un rapport des Pays-Bas (3) qui contenait également un protocole d'essai pour la détermination de la photolyse en milieu aquatique. Les trois propositions faisaient référence aux travaux effectués par ECETOC. En 1981 ECETOC a publié le Technical Report No 3 "An Assessment of Test Methods for Photodegradation of Chemicals in the Environment" (4). Ce rapport traitait des trois compartiments air, milieu aquatique et sol. Donnant suite à une des recommandations faites dans le rapport, treize laboratoires ont participé à un essai circulaire sur la photolyse en milieu aquatique. Les résultats de cet essai furent publiés dans le ECETOC Technical Report No 12 de 1984 (5) et également dans Chemosphere en 1985 (6).

Les documents et rapports précités sont pris en compte dans le document d'orientation ci-présent. D'autres documents ont été utilisés et principalement les suivants:

- $\quad$ US EPA Guideline "Photolysis in aqueous solution in sunlight" (7),

- US EPA Guideline "Laboratory determination of the direct photolysis reaction quantum yield in aqueous solution and sunlight photolysis" (8),

- US EPA Office of Pesticides Programs Standard Evaluation Procedure "Aqueous Photolysis Studies" (9),

- $\quad$ ASTM Method E 896 - 87 "Standard Test Method for Conducting Aqueous Direct Photolysis Tests" (10), et

- Agriculture Canada Guidelines for Determining Environmental Chemistry and Fate of Pesticides (11).

L'objectif du document d'orientation est de situer les trois propositions de Ligne Directrice dans un contexte plus large consistant en des concepts de base de la photochimie applicables au milieu aquatique, des lignes directrices et normes nationales existantes et des résultats de l'essai circulaire de ECETOC. Le document, même si son origine est liée à la soumission de propositions de Lignes Directrices, n'est d'aucune façon à prendre comme une Ligne Directrice embryonnaire. II pourra cependant être utile lorsqu'une activité sur une Ligne Directrice sur la photolyse en milieu aquatique, concertée au niveau de l'OCDE, débutera.

La première partie du document est une introduction générale à la photolyse en milieu aquatique. II s'agit de la transformation directe d'une molecule suite à l'absorption de lumière et non de transformations indirectes dues à l'interaction de la molécule avec d'autres molécules activées ou des radicaux libres. 
Dans l'étude de la photolyse une première étape consiste à déterminer si la molécule est susceptible de se transformer sous l'effet de la lumière. Dans l'eau seules les substances qui absorbent de la lumière entre 290 et $800 \mathrm{~nm}$ peuvent se transformer. L'étendue de la phototransformation dépend du degré de recouvrement entre le spectre d'absorption et le spectre d'émission de la lumière incidente.

Dans une deuxième étape on mesure la cinétique de la photolyse. La vitesse de photolyse dépend de la concentration de la substance et de l'intensité lumineuse. En acceptant que la réaction est d'ordre un, la constante de vitesse est déduite de la diminution de la concentration en fonction du temps. La constante de vitesse ainsi déterminée n'est valable que pour les conditions de la mesure. Ces conditions peuvent être très variées et difficiles à saisir quantitativement.

La vitesse de photolyse peut être déterminée avec plus de précision si l'on connaît l'intensité de la lumière absorbée (le nombre de photons absorbés) et le rendement quantique qui est la fraction des photons absorbés qui résultent en une transformation de la molécule. Ces paramètres sont relativement faciles à établir en laboratoire où l'on peut disposer d'une source de lumière calibrée. Dans l'environnement il n'en est pas de même. La lumière incidente du soleil est très différente suivant le moment, la saison et la latitude. II existe des Tables qui donnent l'intensité moyenne de la lumière solaire incidente pour différentes saisons et situations géographiques. En introduisant ces valeurs il est possible de calculer une vitesse théorique de la photolyse dans des conditions environnementales. Le temps de vie réel d'une molécule dans l'environnement dépend cependant d'une multitude de facteurs qui régissent principalement la pénétration de la lumière dans l'eau.

En troisième lieu on identifie les produits de la photodégradation. Cela est essentiel du point de vue du devenir d'une substance dans l'environnement ainsi que de son écotoxicité, chaque fois que la photolyse apparaît comme un voie significative de dégradation en comparaison avec les autres processus de transformation.

La deuxième partie du document donne un bref apperçu des principes de base de la photochimie et des équations qui sont utilisées dans l'étude de la photolyse aquatique. Ces équations qui sont assez complexes ont été réduites à un strict minimum. Celles qui sont données sont parfois même approximatives. Pour une meilleure compréhension le lecteur est invité à consulter le livre de Asa Leifer, The Kinetics of Environmental Aquatic Photochemistry Theory and Practice (ACS Professional Reference Book, American Chemical Society, 1988).

La troisième partie est une tentative de structurer l'évaluation de la photolyse en milieu aquatique par un schéma comportant quatre étapes (tiers) séquentielles.

Dans le premier tier on essaie d'obtenir une première indication du potentiel que possède la molécule de subir une phototransformation. Cette indication est obtenue en évaluant le degré de recouvrement entre le spectre d'absorption de la molécule et la distribution spectrale de la lumière solaire incidente. II faudra un accord sur un critère d'absorption significative, c.à.d la valeur du coefficient d'absorption molaire à partir de laquelle on estime q'il y a un réel potentiel de photolyse. Le Technical Report No 3 de ECETOC propose la valeur de un, tandis que dans la proposition allemande une valeur de dix est retenue. 
Le deuxième tier utilise l'approche préconisée par US EPA dans le first-tier screening test CFR 40, $\S 796.3700$. Elle est basée sur la connaissance du coefficient d'absorption aux longueurs d'onde qui doivent être prises en considération et de l'intensité de la lumière solaire irradiante. Pour cette dernière il existe des Tables. En supposant une rendement quantique de un, le maximum possible, ces calculs donnent la limite supérieure possible de la constante de vitesse de photolyse.

Le troisième tier fait appel aux méthodes expérimentales. Celles-ci sont de trois ordres: tier 3A- mesures purement cinétiques sans détermination du rendement quantique; tier 3B- détermination du rendement quantique; et tier 3C- mesures cinétiques et détermination du rendement quantique.

La proposition du Royaume-Uni et le rapport néerlandais sont repris en résumés dans le tier 3A. Dans ce tier, une place est faite également à une ligne directrice préliminaire proposée au Japon par le ministère de l'Agriculture pour les dossiers d'homologation de produits phytopharmaceutiques.

Le tier 3B contient les méthodes permettant de déterminer en laboratoire le rendement quantique et, partant de là, de calculer la vitesse théorique de photolyse. II s'agit de la proposition allemande, qui reprend la méthode de l'essai circulaire de ECETOC, et la méthode de la US EPA publiée dans CFR 40, $§ 796.3780$.

Le tier 3C contient seulement la méthode de la US EPA publiée dans CFR 40, $\S 796.3700$ qui comporte deux phases, l'une étant la mesure de la vitesse de photolyse sous l'effet de la lumière solaire et l'autre la mesure de l'intensité lumineuse par actinomètrie, les deux mesures étant faites sur le terrain.

Le quatrième tier consiste en l'identification des produits de la photolyse.

Dans les conclusions à la fin du document il est dit que, du fait des grandes différences qui existent entre les réglements nationaux en matière de données requises pour l'évaluation de l'importance de la transformation d'une substance par photolyse dans l'eau, il sera difficile de s'accorder sur une seule ligne directrice répondant à tous les besoins. 


\section{INTRODUCTION}

In 1992 the German Umweltbundesamt submitted a proposal for a Guideline, "Phototransformation of Chemicals in Water - Direct Phototransformation" (1). In 1993 the UK Department of the Environment followed with another proposal, "Determination of the Stability of a Substance to Simulated Sunlight" (2). In 1992 a Dutch report, "Sunlight Induced Degradation of Chemicals in Surface Water" (3), which contained a test protocol, was also communicated to the OECD Secretariat. The two proposals and the report referred to work done by ECETOC. In 1981, ECETOC published Technical Report $\mathrm{N}^{\circ} 3, A n$ Assessment of Test Methods for Photodegradation of Chemicals in the Environment (4). The methods reviewed in the ECETOC report relate to all three compartments of the environment: air, water and soil. Under the aegis of ECETOC, and in the follow-up to one of the recommendations of the report, thirteen laboratories performed a ring test of phototransformation in water. The results were published in 1984 as ECETOC Technical Report $N^{\circ} 12$ (5) and were also published in 1985 in Chemosphere (6).

These are the main documents used by the Secretariat in developing this Guidance Document, but other documents were also consulted and used. They include:

- the US EPA Guideline, "Photolysis in Aqueous Solution in Sunlight" (7);

- the US EPA Guideline, "Laboratory Determination of the Direct Photolysis Reaction Quantum Yield in Aqueous Solution and Sunlight Photolysis" (8);

- the US EPA Office of Pesticides Programs Standard Evaluation Procedure, "Aqueous Photolysis Studies" (9);

- ASTM Method E 896-87 "Standard Test Method for Conducting Aqueous Direct Photolysis Tests" (10); and

- the Agriculture Canada Guidelines for Determining Environmental Chemistry and Fate of Pesticides (11).

This Guidance Document should not be considered a general introduction to phototransformation in water. ${ }^{1}$ It is rather an attempt to group the existing methods and the three proposals in a system of tiers according to the increasing importance of the acquired experimental set-up.

\footnotetext{
${ }^{1}$ A detailed discussion of the theory and practice of the kinetics of environmental aquatic photochemistry can be found in the book by Asa Leifer mentioned in the Foreword (12).
} 
The first tier consists in recording the UV-VIS spectrum and determining the molar absorption coefficient.

Where there is sufficient absorption (a criterion which has to be agreed), a second tier could be based on the US EPA first tier screening test (7).

Tier 3 contains three options:

- 3A: Purely kinetic experiments, in line with the proposals and methods from the UK (2), Netherlands (3) and Japan (13);

- 3B: Determination of the quantum yield, using artificial light according to the German proposal (1) and the ECETOC report (5) (6), as well as the US EPA method (8);

- 3C: The US EPA second tier screening test using sunlight (7).

Tier 4 consists of the analytical determination of transformation products. 


\section{PART 1. PHOTOCHEMICAL PROCESSES IN THE AQUATIC ENVIRONMENT AND METHODS FOR ESTIMATING AND MEASURING PHOTOCHEMICAL TRANSFORMATION}

\section{Photochemical degradation of chemicals in the environment}

Under the influence of sunlight, chemicals may undergo transformation in the three compartments air, water and soil. In primary photoreactions, light interacts with the chemical directly through absorption and indirectly through energy, electron and $\mathrm{H}$-atom transfer from an excited photosensitizer. In secondary photoreactions the chemical reacts with photolytically generated reactive species.

Under tropospheric air conditions, the main photochemical processes at work are secondary reactions of the chemical with hydroxyl radicals and ozone. Photolysis, the direct transformation of the parent molecule activated through the absorption of a photon, is of less importance. Phototransformation in air was addressed in OECD Environment Monograph $\mathrm{N}^{\circ} 61$ (14).

The situation in the water compartment is very different from that in air. Biodegradation and hydrolysis, processes that are not relevant in air, are by far the most likely pathways for the degradation of chemicals. However, phototransformation is a significant degradation pathway for many chemicals in water.

In soil there are many possibilities for degradation, both biotic and abiotic. Photodegradation occurs at the surface of the soil and warrants consideration in its own right. It is not considered in this document.

\section{Photodegradation in water}

Primary photodegradation in water can be divided into direct phototransformation (photolysis), in which the chemical itself absorbs light, becomes electronically excited and undergoes subsequent transformation, and indirect phototransformation, whereby energy, electrons and $\mathrm{H}$-atoms are transferred from an excited photosensitiser (in environmental water, mainly humic and fulvic acids) to the chemical. Direct photolysis can be assessed using techniques that are well developed. The indirect phototransformation of chemicals in the aquatic environment is not considered in this document. Many different processes are involved, and the methods for evaluating the relevance of these processes are not well tested yet. 
There are factors in environmental water that can complicate the degradation process of the molecule under study. Secondary reactions with radicals (mainly hydroxyl- and peroxy-radicals) and with hydrogen peroxide can occur, and foreign materials that strongly absorb light may reduce the available light intensity to ineffective levels.

\section{Testing procedures and estimation methods}

A distinction is made between photolability, i.e. the potential for photochemical change, and the photochemical mechanisms which, given sufficiently intense irradiation, are a consequence of the photolability. To cover the complete process, an appropriate sequential testing procedure would include:

- identification of photolability and screening tests for photolysis;

- accurate determination of the kinetic parameters of photolysis and extrapolation to environmental conditions; and

- identification of the products of photodegradation.

Estimation methods based on structure-activity relationships are very valuable for the evaluation of photochemical reaction rates in air. This is not the case here. As stated by J.C. Harris (15): "The complexity of the network of possible reaction pathways (in water) makes development of structure-reactivity correlations a formidable task."

\section{The identification of photolability and screening tests for photolysis}

No direct photoreaction is possible without absorption of light quanta. Only quanta of UV/visible light are energetic enough to break bonds between atoms in a molecule and only the wavelength range $290-800 \mathrm{~nm}$ is relevant for photolysis in the water compartment. As a consequence, chemicals that absorb light significantly only in the UV region below $290 \mathrm{~nm}$ and in the infra-red above $800 \mathrm{~nm}$ cannot undergo direct photolysis in the water compartment. Whether a chemical has the potential for direct photolysis will depend in the first place on the degree of overlap between the ultraviolet/visible absorption spectrum of the chemical and the emission spectrum of the incident sunlight in the wavelength range 290-800 nm. Screening tests have been proposed for assessing the likelihood of photolysis under environmental conditions.

\section{Determination of the rate of direct phototransformation}

The rate of photolysis depends on the concentration of the chemical. First order kinetics are assumed, and a rate constant can be derived from the decrease of concentration with time. A rate constant determined in this fashion holds only for the conditions of the measurement, which can be extremely variable and also difficult to quantify. Moreover, to obtain valid kinetic data, one must be sure that the only phenomenon measured is photolysis, with the exclusion of any other process. 
For a number of reasons, the experimental determination of rates of photolysis needs to be made at low concentrations of the chemical (in general, concentrations of less than $10^{-4}$ mole . litre $e^{-1}$ are used). First, the concentrations of chemicals in environmental water are generally low and the environmental relevance of experiments is thus increased by using low concentrations of the test chemical. Second, absorption of light occurs at, or close to, the surface of the water, where the light enters. Molecules that are further from the water surface are protected from light. With low concentrations, this inner filter effect can be neglected. Third, the higher the concentration of the chemical, the greater the possible contribution of chain reactions induced by free radicals.

\section{Basic parameters}

The rate of photolysis can also be calculated from the number of light quanta absorbed per unit time (the absorbed light intensity) multiplied by the fraction of absorbed photons that lead to the transformation of the irradiated molecule (the photolysis quantum yield).

The absorbed light intensity depends on the intensity and spectral distribution of the incident light and the absorption spectrum of the chemical (the absorption coefficients at the different wavelengths of the absorption bands). In laboratory experiments, the characteristics of the incident light depend on the light source and the distance between source and irradiated sample. In the environment, the incident light is sunlight with very different characteristics in different geographical and seasonal situations.

The formation of a photochemically excited state is a necessary but not sufficient condition for producing a change in the structure of a molecule. The photochemical transformation competes with radiative and radiationless deactivation of the excited molecule. The efficiency of each process is expressed in terms of a quantum yield which is the ratio of the number of excited molecules undergoing a particular process to the number of photons absorbed. The sum of all quantum yields is unity. The term "quantum yield" appearing hereafter in the document is meant to be understood as the photolysis quantum yield.

Absorption coefficients and quantum yield are compound-specific parameters.

\section{Theoretical rate and lifetime}

Knowledge of the compound-specific parameters, when coupled with the knowledge of the spectral distribution and average intensity of the incident sunlight, enables the prediction of a theoretical rate of photolysis and a theoretical lifetime or half-life. Sunlight intensities are very different, according to geographical situation and season. Yearly averaged midday intensities of sunlight, corrected for reflection from the water's surface, have been computed for North America between 20 and $50^{\circ} \mathrm{N}(16)$ and for Central Europe (17). Theoretical lifetimes calculated on the basis of these values of sunlight intensities, although valid only for the top layer of an aqueous system, are very useful as estimates of the persistence of chemicals in water. 


\section{The rate of photolysis under actual environmental conditions}

The real lifetime depends on the penetration of light into the water, which in turn depends on a host of factors, e.g. material in suspension, the presence of other light-absorbing substances and active species such as radicals, etc. Computer programmes, e.g. SOLAR (16) and ABIWAS (Abbau im Wasser) (17), are available for calculating the lifetime in a particular aquatic system as a function of system-related variables.

\section{Identification of the main products of photolysis}

From the viewpoint of chemical fate and ecotoxicity, knowledge of the degradation products is essential whenever photolysis appears to be a significant pathway of degradation relative to other environmental transformation processes. It is a requirement in schemes for the assessment of pesticides because of the likely magnitude of environmental concentrations that result from pesticide use. The main products of the photolytical process which are not further photodegradable can be identified using traditional physico-chemical and analytical methods. For purposes of analysis, it may be necessary to use higher concentrations than those used in the kinetic experiments. 


\section{PART 2. $\quad$ BASIC PRINCIPLES AND FORMULAS}

The Grotthus-Draper law states that only light which is absorbed by a molecule can be effective in producing a chemical transformation of the molecule. The Stark-Einstein law states that only one molecule is activated to an excited state for each quantum of light absorbed.

The rate of photolysis, assuming first order kinetics, is given by:

$$
-\frac{d c}{d t}=k_{p} c
$$

where $\quad c$ is the concentration in mole. litre $^{-1}$

$t$ is the time of irradiation in seconds

$\mathrm{k}_{\mathrm{p}}$ is the first order photolysis rate constant in $\mathrm{s}^{-1}$

The relation between the rate constant and the half-life is given by:

$$
t_{1 / 2}=\frac{0.693}{k_{p}}
$$

The rate can also be expressed in terms of $\Phi$, the photolysis quantum yield, which is the ratio of the number of molecules that undergo photolysis over the number of photons absorbed (or the number of moles transformed over the number of einsteins absorbed). When monochromatic light of wavelength $\lambda$ is used, the rate can be expressed as:

$$
-\frac{\mathrm{dc}}{\mathrm{dt}}=10^{3} \cdot \Phi_{\lambda} \cdot \mathrm{l}_{\mathrm{a}(\mathrm{t}, \lambda)}
$$

where $\Phi_{\lambda}$ is the quantum yield at wavelength $\lambda$, in mole . einstein ${ }^{-1}$

$\mathrm{I}_{\mathrm{a}(\mathrm{t}, \lambda)}$ is the intensity of absorbed light of wavelength $\lambda$ in the irradiated volume, expressed in einstein. $\mathrm{cm}^{-3} \cdot \mathrm{s}^{-1}$

$10^{3}$ converts mole. $\mathrm{cm}^{-3}$ to mole. litre ${ }^{-1}$ 
When incident light of intensity $I_{0}$ passes through a solution, the intensity $I$ of transmitted light per unit surface is given by the Beer-Lambert law:

$$
I_{(\lambda)}=I_{o(\lambda)} \cdot 10^{-\varepsilon(\lambda) c d}
$$

where $\quad \varepsilon_{(\lambda)}$ is the molar decadic absorption coefficient at wavelength $\lambda$, expressed in litre. $\mathrm{mole}^{-1} \cdot \mathrm{cm}^{-1}$

$\mathrm{d}$ is the optical path in $\mathrm{cm}$

$\mathrm{c}$ is the concentration of the absorbing substance in mole . litre ${ }^{-1}$ the intensities are in photon or einstein. $\mathrm{cm}^{-2} \cdot \mathrm{s}^{-1}$.

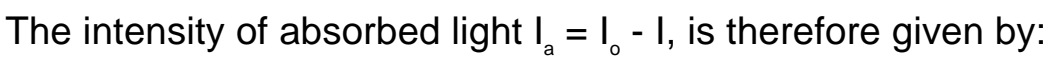

$$
I_{a(\lambda)}=I_{o(\lambda)} \cdot\left[1-10^{-e(\lambda) c d}\right]
$$

The intensity of absorbed light per unit volume is given by:

$$
\mathrm{I}_{\mathrm{a}(\lambda)}=\frac{\mathrm{I}_{\mathrm{o}(\lambda)}}{\mathrm{d}}\left[1-10^{-\varepsilon(\lambda) \mathrm{cd}}\right]
$$

When the optical path is $1 \mathrm{~cm}$, Equations 5 and 6 are simplified to:

$$
\mathrm{I}_{\mathrm{a}(\lambda)}=\mathrm{I}_{\mathrm{o}(\lambda)} \cdot\left[1-10^{-\mathrm{e}(\lambda) \mathrm{c}}\right]
$$

and the value of $I_{a(\lambda)}$ can be substituted in Equation 3:

$$
-\frac{\mathrm{dc}}{\mathrm{dt}}=10^{3} \cdot \Phi_{\lambda} \cdot \mathrm{l}_{\mathrm{o}(\lambda)} \cdot\left[1-10^{-\varepsilon(\lambda) \mathrm{c}}\right]
$$

When the absorbance, which is the product of e.c.d, is low and a unit volume is considered, Equation 6 can be approximated by:

$$
\mathrm{I}_{\mathrm{a}(\lambda)}=\mathrm{I}_{\mathrm{o}(\lambda)} \cdot \varepsilon_{\lambda} \cdot \mathrm{c} \cdot \ln 10
$$




$$
=2.3 \mathrm{I}_{\mathrm{o}(\lambda)} \cdot \varepsilon_{\lambda} \cdot \mathrm{C}
$$

(Equation 9)

The rate Equation 8 can then be written as:

$-\frac{\mathrm{dc}}{\mathrm{dt}}=2300 \cdot \Phi_{\lambda} \cdot \mathrm{l}_{\mathrm{o}(\lambda)} \cdot \varepsilon_{\lambda} \cdot \mathrm{c}$

and the rate constant as:

$\mathrm{k}_{\mathrm{p}}=2300 \cdot \Phi_{\lambda} \cdot \mathrm{l}_{\mathrm{o}(\lambda)} \cdot \varepsilon_{\lambda}$

(Equation 11)

When sunlight or polychromatic light is used in the experiment, integration over the entire relevant wavelength range is necessary:

$$
\mathrm{k}_{\mathrm{p}}=2300 \int_{\lambda_{1}}^{\lambda_{2}} \Phi \cdot \mathrm{l}_{\mathrm{o}(\lambda)} \cdot \varepsilon_{(\lambda)} \cdot \mathrm{d} \lambda
$$

where $\Phi$ is the quantum yield of disappearance under excitation extending from $\lambda_{1}$ to $\lambda_{2}$, expressed in mole . einstein ${ }^{-1}$

$I_{o(\lambda)}$ is the intensity of incident light of wavelength $\lambda$ expressed in einstein $\cdot \mathrm{cm}^{-2} \cdot \mathrm{s}^{-1} \cdot \mathrm{nm}^{-1}$ 


\section{PART $3 . \quad$ A TIER SYSTEM OF TESTING}

\section{TIER $1 \quad$ UV-VIS SPECTRUM AND MOLAR ABSORPTION COEFFICIENTS}

The UV-VIS spectrum in the wavelength range $290-800 \mathrm{~nm}$ is recorded and the molar absorption coefficients are determined according to OECD Guideline 101. The spectrum of an ionisable substance should be recorded at three different $\mathrm{pH}$ values in the range 4 to 9 . Measurements should be made at the wavelength intervals set out in the Annex, Table 1.

The extent of overlap between the absorption bands of a substance and the spectral distribution of the incident sunlight gives a first indication of the potential for photolysis to take place.

If there is "significant" absorption, one proceeds to Tier 2. Two proposed rules of thumb to use in determining whether absorption is significant are a value of one or more for the molar absorption coefficient (in litre . $\mathrm{mol}^{-1} \mathrm{~cm}^{-1}$ ) above $295 \mathrm{~nm}$ (ECETOC Technical Report N 3 ) and a value of ten (German proposal). There should be agreement on the criterion.

\section{TIER $2 \quad$ UPPER LIMIT FOR THE DIRECT PHOTOLYSIS SUNLIGHT RATE CONSTANT}

This procedure is set out in the US EPA first-tier screening test CFR 40, $\$ 796.3700$ (7). The method is based on principles developed by Zepp and Cline (16). The basic equation is:

$$
\mathrm{k}_{\mathrm{p}}=\Phi \mathrm{k}_{\mathrm{a}},
$$

where $\Phi$ is the quantum yield, considered to be independent of the wavelength, and

$k_{a}$ is the light absorption rate constant, the sum of the $k_{a(\lambda)}$ values for all wavelengths of sunlight absorbed by the chemical

$$
\begin{aligned}
& \mathrm{k}_{\mathrm{a}}=\sum \mathrm{k}_{\mathrm{a}(\lambda)} \\
& \lambda \\
& \mathrm{k}_{\mathrm{a}} \text { can be calculated from } \mathrm{k}_{\mathrm{a}}=\underset{\lambda}{\sum} \varepsilon_{\lambda} \mathrm{L}_{\lambda},
\end{aligned}
$$


where

$L_{\lambda}$ is the solar irradiance in water at shallow depths for a water body under clear sky conditions and is given as a function of latitude $\left(20^{\circ} \mathrm{N}, 30^{\circ} \mathrm{N}, 40^{\circ} \mathrm{N}\right.$ and $\left.50^{\circ} \mathrm{N}\right)$ and season of the year (Annex: Tables 2, 3, 4 and 5, values applicable to North America ${ }^{2}$ ). The solar irradiance is proportional to the average light flux that is available to cause photoreaction in a wavelength interval centred at $\lambda$ over a $24 \mathrm{~h}$ day. It is given in units of $10^{-3}$ einstein. $\mathrm{cm}^{-2}$. day ${ }^{-1}$. The summation is done over the wavelengths $290-800 \mathrm{~nm}$.

The rate constant $\mathrm{k}_{\mathrm{p}}$ is given by $\mathrm{k}_{\mathrm{p}}=\underset{\lambda}{\Phi \varepsilon_{\lambda} \mathrm{L}_{\lambda}}$

(Equation 16)

Assuming a value of one for the quantum yield, which is the maximum possible, $\mathrm{k}_{\mathrm{p}(\max )}$, the upper limit of the photolysis rate constant (which also gives the lower limit of the halflife), is obtained:

$$
\mathrm{k}_{\mathrm{p}(\max )}=\underset{\lambda}{\sum \varepsilon_{\lambda} \mathrm{L}_{\lambda}}
$$

(Equation 17)

If the result indicates that photolysis is possibly an important process relative to other transformation processes (e.g. biodegradation, hydrolysis, oxidation), it is recommended that Tier 3 tests be carried out.

\section{TIER 3A KINETIC EXPERIMENTS NOT INCLUDING THE DETERMINATION OF THE QUANTUM YIELD}

Stability of a substance to simulated sunlight: a proposal from the United Kingdom (2)

An aqueous solution of the test substance is exposed to light from a solar simulator, the light output of which is known or measured. The proposed method is similar to that described by Parker and Leahey (18). Two kinetic experiments are usually necessary. A preliminary kinetic experiment is run for seven days. If the extent of degradation is less than 10 per cent, it is concluded that the substance is relatively stable to light. Otherwise a definitive kinetic experiment is run for 30 days or up to 75 per cent degradation, whichever is the shorter duration. The nature of the breakdown products may be studied.

Conditions for the kinetic experiments are specified as follows:

- light source: a solar simulator, generally a xenon arc of known output, measured by a spectroradiometer, by actinometry, or according to the manufacturer's specification; 12 hour light/dark cycles;

${ }^{2}$ Solar irradiance data for Central Europe are also available (17). 
- initial concentration of the test substance: normally less than $10^{-2}$ mole . litre ${ }^{-1}$; not giving rise to such high absorption of the incident radiation that absorption is not uniform in the test vessel; sufficient for the analytical determinations;

- medium: sterile; double-distilled water and organic solvents of analytical grade (acetonitrile is suitable) maintained at $\leq 1 \%$; buffered at $\mathrm{pH} 7$ or at the $\mathrm{pH}$ where the hydrolysis rate is lowest;

- test vessels: duplicate; one control kept in darkness;

- reference compound: pentachlorophenol;

- temperature: $25 \pm 1^{\circ} \mathrm{C}$.

\section{Sunlight-induced degradation of chemicals in surface water: a proposal from the Netherlands (3)}

This approach is identical with that of the UK proposal, namely the measurement of the rate of photolysis using a solar simulator of known intensity. The equipment is relatively simple.

Conditions for the kinetic experiments are specified as follows:

- light source: MSR lamp in a reflector unit provided with a filter; intensity $65 \mathrm{~W} \mathrm{~m}^{-2}$ measured in close proximity to the samples;

- initial concentration of the test substance: $10^{-5}$ mole.$l^{-1}$;

- medium: reconstituted water according to O.J. of EC L251, 146-154 (1984);

- test vessels: round quartz tubes, $1.4 \times 20 \mathrm{~cm}$, containing $5 \mathrm{ml}$ of solution;

- apparatus: merry-go-round.

The authors of the report emphasize the importance of standardization. They explain the origin of the method as follows: "Intensity and spectral distribution of daylight are highly dependent on time of the day, season, ozone layer thickness, cloud cover, latitude, etc. If these parameters are not standardized, it is necessary to determine the quantum yield of the photodegradation of a chemical as a function of the wavelength in order to estimate the half-life. The half-life can then be calculated, for a given set of light conditions, provided that the absorption spectrum of the chemical is also taken into account. However, such a method is not attractive because it is complex to perform with the usual laboratory equipment and without specialized staff." They then state that a more simple method can be developed. They refer to the related problem of the photostability of paints, plastics, textiles, etc, exposed to sunlight all year round. In that case, the Commission Internationale d'Eclairage has agreed on one spectral distribution and total intensity of sunlight. A solar simulator approximately meeting these characteristics has become available and was used in the Dutch study. 


\section{Japanese tentative guidance for the study of the photolysis of agricultural pesticides in water (13)}

This guidance is aimed at the measurement of the half-life and is very broad. The following is set out:

- light source: a solar simulator, whose spectral distribution and light density are similar to those of natural sunlight;

- initial concentration of the active ingredient: sufficient for the analytical determinations; for sparingly soluble compounds, an organic vehicle having negligible photosensitising capacity can be used in minimal volume;

- medium: both natural water and sterilised distilled water should be used;

- test vessels: in quartz; one control in darkness;

- temperature: room temperature;

- analytical determinations: active ingredient and breakdown products, if necessary.

\section{TIER 3B THE DETERMINATION OF THE QUANTUM YIELD IN THE LABORATORY (6) The ECETOC ring test (5) (6) and the proposal from Germany (1)}

Using this approach, the compound-specific parameters of photolysis are determined in the laboratory. These parameters are the absorption coefficient, which dictates how much of the incident light is absorbed, and the quantum yield, which links the amount of light absorbed to the amount of chemical transformed.

The basic equation is Equation 3, which is applicable to monochromatic light. When polychromatic light is used, the integrated form of this equation applies:

$$
-\frac{d c}{d t}=\int_{\lambda_{1}}^{\lambda_{2}} \Phi_{(\lambda)} \cdot l_{a(\lambda)} \cdot d \lambda
$$

The quantum yield is frequently found to be constant over certain wavelength intervals. Equation 18 can be simplified to:

$$
-\frac{\mathrm{dc}}{\mathrm{dt}}=\Phi \int_{\lambda_{1}}^{\lambda_{2}} \mathrm{l}_{\mathrm{a}(\lambda)} \cdot \mathrm{d} \lambda
$$

The quantum yield can thus be calculated from the rate of photolysis, which is measured using analytical techniques and the absorbed light intensity $I_{a(\lambda)}$ integrated over 
the relevant wavelength interval. To calculate the absorbed light intensity, precise values of the absorption coefficient and the spectral distribution and intensity of the incident light are needed. The measurement of absorption coefficients is commonly practised in laboratories. The precise measurement of the incident light intensity requires the use of an actinometer. The actinometer consists of a photoreactive solution of known quantum yield. The intensity of the incident light is derived from the measured rate of photoreaction of the actinometer.

\section{Equipment}

The technique recommended by ECETOC for the ring test was developed by Prof. J. Lemaire and the Laboratoire de Photochimie at the University of Clermont-Ferrand (France). An apparatus is required which permits the irradiation of the chemical by polychromatic or monochromatic light. Whatever apparatus is used, merry-go-round (described in Reference 8) or optical bench, it should be ensured that the sample and the actinometric solution receive equal amounts of radiation. In the apparatus recommended for the ring test, standard quartz cuvettes turned around a centrally located light source.

Further requirements are a double-beam spectrophotometer and analytical equipment.

\section{US EPA method CFR 40, $\S 796.3780$ for laboratory determination of the direct photolysis quantum yield in aqueous solution (8)}

This approach is basically identical with that of the ECETOC ring test. The procedure involves the simultaneous photolysis of a solution of the test chemical and an actinometer solution in a merry-go-round apparatus (using tubes) or on an optical bench (using flat cells) under monochromatic irradiation. The method is described in great detail.

\section{TIER 3C MEASURING RATE AND QUANTUM YIELD USING SUNLIGHT: THE SECOND-TIER EPA TEST CFR 40, § 796.3700 (7)}

Using this approach, the experiments are performed using direct sunlight. There are two phases. In phase one, the test chemical is photolyzed in sunlight in order to obtain an approximate rate constant. The intensity of the light incident on the sample is not measured in this phase. In phase two, an actinometer is exposed to the incident light and the rate constant for this actinometer is adjusted to match the approximate rate of the test chemical solution. This is done by adjusting the concentration of the actinometer solution. By applying Equation 16 to the test chemical and the actinometer, the quantum yield of the test chemical can be calculated.

\section{TIER $4 \quad$ IDENTIFICATION OF THE PRODUCTS OF PHOTOLYSIS}

The Guidelines of Agriculture Canada require the identification of any photoproduct present at any time during the study at 10 per cent or more of the initial concentration. The identification must be done with radio-labelled pesticide. 


\section{CONCLUSIONS}

In the assessment of the photolytical behaviour of a chemical substance in water, there exist different levels of complexity. The levels are:

- a crude assessment, such as whether the chemical can be photolyzed (Tiers 1 and 2);

- an assessment based on the experimentally determined half-life of the chemical and the description of the conditions of the experiment (Tier 3A); and

- a prediction of the theoretical rate in the environment (Tiers $3 \mathrm{~B}$ and $3 \mathrm{C}$ );

- the identification of breakdown products.

Given that the regulatory data requirements are different between countries and between categories of chemicals (e.g. industrial chemicals and pesticides), it will certainly be very difficult to arrive at a single Guideline covering all needs. 


\section{LITERATURE}

(1) Phototransformation of Chemicals in Water - Direct Phototransformation, Umweltbundesamt, Berlin, September 1990.

(2) Determination of the Stability of a Substance to Simulated Sunlight, Department of the Environment, London, July 1993.

(3) Beijersbergen van Henegouwen G.M.J., Persons, C.C.M. and Meulemans, C.C.E., Sunlight Induced Degradation of Chemicals in Surface Water, Final Report, Leiden, Netherlands, December 1990.

(4) Technical Report $\mathrm{N}^{\circ} 3$, An Assessment of Test Methods for Photodegradation of Chemicals in the Environment, ECETOC, Brussels, 1981.

(5) Technical Report $N^{\circ} 12$, The Phototransformation of Chemicals in Water: Results of a Ring test, ECETOC, Brussels, June 1984.

(6) Lemaire, J., Guth, J.A., Klais, O., Leahey, J., Merz, W., Philp, J., Wilmes, R. and Wolff, C.J.M., Chemosphere, Vol. 14, N 1, 53-77, 1985, Pergamon Press Ltd.

(7) US EPA CFR 40, § 796.3700, Photolysis in Aqueous Solution in Sunlight.

(8) US EPA CFR 40, $\S 796.3780$, Laboratory Determination of the Direct Photolysis Reaction Quantum Yield in Aqueous Solution and Sunlight Photolysis.

(9) US EPA Pesticide Assessment Guidelines, Subdivision N, Chemistry: Environmental Fate, Office of Pesticides and Toxic Substances, October 1982, Washington, D.C., and Hazard Evaluation Division, Standard Evaluation Procedure "Aqueous Photolysis Studies", Office of Pesticides Programs, June 1985, Washington, D.C.

(10) ASTM E 896-87, Standard Test Method for Conducting Aqueous Direct Photolysis Tests, American Society for Testing and Materials, Philadelphia, PA.

(11) Agriculture Canada, Guidelines for Determining Environmental Chemistry and Fate of Pesticides, T-1-255, October 30, 1987.

(12) Leifer, A., The Kinetics of Environmental Aquatic Photochemistry, Theory and Practice, ACS Professional Reference Book, American Chemical Society, 1988.

(13) Tentative Guidance for the Study of Photolysis of Agricultural Pesticides in Water. Annexed to Comments from Japan on the Draft OECD Guidance on Direct Phototransformation of Chemicals in Water, May 1995. 
(14) The Rate of Photochemical Transformation of Gaseous Organic Compounds in Air Under Tropospheric Conditions, OECD Environment Monograph N 61, Paris, 1992.

(15) Harris, J.C., Rate of Aqueous Photolysis, in: Handbook of Chemical Estimation Methods, W.J. Lyman, W.F. Reehl and D.H. Rosenblatt, Eds, pp 8-1 to 8-43, McGraw-Hill Book Company, 1982.

(16) Zepp, R.G. and Cline, D.M., Rates of Direct Photolysis in Aquatic Environment, Environmental Science and Technology, Vol. 11, 359-366 (1977).

(17) Frank, R. and Klöpffer, W., Ecotox. Environ. Safety, Vol.17, 323-332, 1988.

(18) Parker, S. and Leahey, J.P., Proceedings of the 1988 Brighton Crop Protection Conference, 663. 


\section{ANNEX}

Table 1: Wavelength centre and intervals for $L_{\lambda}$

\begin{tabular}{|c|c|c|c|}
\hline$\lambda$ centre $(\mathrm{nm})$ & Interval from (nm) & Range to $(\mathrm{nm})$ & $\Delta \lambda(\mathrm{nm})$ \\
\hline 297.5 & 296.2 & 298.7 & 2.5 \\
\hline 300.0 & 298.7 & 301.2 & 2.5 \\
\hline 302.5 & 301.2 & 303.7 & 2.5 \\
\hline 305.0 & 303.7 & 306.2 & 2.5 \\
\hline 307.5 & 306.2 & 308.7 & 2.5 \\
\hline 310.0 & 308.7 & 311.2 & 2.5 \\
\hline 312.5 & 311.2 & 313.7 & 2.5 \\
\hline 315.0 & 313.7 & 316.2 & 2.5 \\
\hline 317.5 & 316.2 & 318.7 & 2.5 \\
\hline 320.0 & 318.7 & 321.2 & 2.5 \\
\hline 323.1 & 321.2 & 325.0 & 3.8 \\
\hline 330.0 & 325.0 & 335.0 & 10.0 \\
\hline 340.0 & 335.0 & 345.0 & 10.0 \\
\hline 350 & 345.0 & 355.0 & 10.0 \\
\hline 360 & 355.0 & 365.0 & 10.0 \\
\hline 370 & 365.0 & 375.0 & 10.0 \\
\hline 380 & 375.0 & 385.0 & 10.0 \\
\hline 390 & 385.0 & 395.0 & 10.0 \\
\hline 400 & 395.0 & 405.0 & 10.0 \\
\hline 410 & 405.0 & 415.0 & 10.0 \\
\hline 420 & 415.0 & 425.0 & 10.0 \\
\hline 430 & 425.0 & 435.0 & 10.0 \\
\hline 440 & 435.0 & 445.0 & 10.0 \\
\hline 450 & 445.0 & 455.0 & 10.0 \\
\hline 460 & 455.0 & 465.0 & 10.0 \\
\hline 470 & 465.0 & 475.0 & 10.0 \\
\hline 480 & 475.0 & 485.0 & 10.0 \\
\hline 490 & 485.0 & 495.0 & 10.0 \\
\hline 500 & 495.0 & 505.0 & 10.0 \\
\hline 525 & 512.5 & 537.5 & 25 \\
\hline 550 & 537.5 & 562.5 & 25 \\
\hline 575 & 562.5 & 587.5 & 25 \\
\hline 600 & 587.5 & 612.5 & 25 \\
\hline 625 & 612.5 & 637.5 & 25 \\
\hline 650 & 637.5 & 662.5 & 25 \\
\hline 675 & 662.5 & 687.5 & 25 \\
\hline 700 & 687.5 & 712.5 & 25 \\
\hline 750 & 725.0 & 775.0 & 50 \\
\hline 800 & 775.0 & 825.0 & 50 \\
\hline
\end{tabular}

Source: Reference 7. 
Table 2: $L_{\lambda}$ values for latitude $20^{\circ} \mathbf{N}^{1,2,3}$ (North America)

\begin{tabular}{|c|l|l|l|l|}
\hline$\lambda$ centre $(\mathrm{nm})$ & Spring & Summer & Fall & Winter \\
\hline 297.5 & $1.10(-4)$ & $1.52(-4)$ & $7.77(-5)$ & $3.71(-5)$ \\
300.0 & $4.06(-4)$ & $5.26(-4)$ & $2.96(-4)$ & $1.62(-4)$ \\
302.5 & $1.10(-3)$ & $1.35(-3)$ & $8.21(-4)$ & $4.99(-4)$ \\
305.0 & $2.37(-3)$ & $2.79(-3)$ & $1.79(-3)$ & $1.17(-3)$ \\
307.5 & $4.24(-3)$ & $4.86(-3)$ & $3.24(-3)$ & $2.25(-3)$ \\
310.0 & $6.65(-3)$ & $7.45(-3)$ & $5.13(-3)$ & $3.72(-3)$ \\
312.5 & $9.42(-3)$ & $1.04(-2)$ & $7.33(-3)$ & $5.47(-3)$ \\
315.0 & $1.24(-2)$ & $1.35(-2)$ & $9.68(-3)$ & $7.40(-3)$ \\
317.5 & $1.54(-2)$ & $1.66(-2)$ & $1.21(-2)$ & $9.38(-3)$ \\
320.0 & $1.82(-2)$ & $1.96(-2)$ & $1.44(-2)$ & $1.13(-2)$ \\
323.1 & $3.23(-2)$ & $3.45(-2)$ & $2.55(-2)$ & $2.04(-2)$ \\
330.0 & $1.10(-1)$ & $1.17(-1)$ & $8.75(-2)$ & $7.08(-2)$ \\
340.0 & $1.37(-1)$ & $1.45(-1)$ & $1.10(-1)$ & $9.02(-2)$ \\
350.0 & $1.52(-1)$ & $1.60(-1)$ & $1.22(-1)$ & $1.01(-1)$ \\
360.0 & $1.67(-1)$ & $1.76(-1)$ & $1.35(-1)$ & $1.12(-1)$ \\
370.0 & $1.78(-1)$ & $1.88(-1)$ & $1.45(-1)$ & $1.21(-1)$ \\
380.0 & $1.89(-1)$ & $2.00(-1)$ & $1.55(-1)$ & $1.30(-1)$ \\
390.0 & $1.79(-1)$ & $1.89(-1)$ & $1.46(-1)$ & $1.22(-1)$ \\
400.0 & $2.57(-1)$ & $2.71(-1)$ & $2.09(-1)$ & $1.75(-1)$ \\
410.0 & $3.38(-1)$ & $3.57(-1)$ & $2.76(-1)$ & $2.31(-1)$ \\
420.0 & $3.47(-1)$ & $3.67(-1)$ & $2.84(-1)$ & $2.38(-1)$ \\
430.0 & $3.35(-1)$ & $3.54(-1)$ & $2.74(-1)$ & $2.30(-1)$ \\
440.0 & $3.95(-1)$ & $4.18(-1)$ & $3.25(-1)$ & $2.72(-1)$ \\
450.0 & $4.45(-1)$ & $4.70(-1)$ & $3.65(-1)$ & $3.07(-1)$ \\
460.0 & $4.50(-1)$ & $4.75(-1)$ & $3.70(-1)$ & $3.11(-1)$ \\
470.0 & $4.65(-1)$ & $4.91(-1)$ & $3.83(-1)$ & $3.22(-1)$ \\
480.0 & $4.76(-1)$ & $5.03(-1)$ & $3.92(-1)$ & $3.31(-1)$ \\
490.0 & $4.50(-1)$ & $4.76(-1)$ & $3.72(-1)$ & $3.13(-1)$ \\
500.0 & $4.59(-1)$ & $4.85(-1)$ & $3.80(-1)$ & $3.20(-1)$ \\
525.0 & 1.21 & 1.28 & 1.00 & $8.48(-1)$ \\
550.0 & 1.26 & 1.33 & 1.05 & $8.83(-1)$ \\
575.0 & 1.27 & 1.35 & 1.06 & $8.92(-1)$ \\
600.0 & 1.29 & 1.36 & 1.07 & $9.05(-1)$ \\
625.0 & 1.29 & 1.37 & $9.15(-1)$ \\
650.0 & 1.30 & 1.38 & 1.08 & $9.24(-1)$ \\
675.0 & 1.30 & 1.38 & 1.09 & $9.21(-1)$ \\
700.0 & 1.29 & 1.36 & 1.08 & 1.71 \\
750.0 & 2.48 & 2.62 & 2.08 & \\
800.0 & 2.38 & 2.51 & & \\
\hline
\end{tabular}

Notes:

1. Units of $L_{\lambda}$ are $10^{-3}$ einsteins $\mathrm{cm}^{-2}$ day ${ }^{-1}$. Multiplication of $L_{\lambda}$ by $\varepsilon_{\lambda}$ in units of molar-1 $^{-1} \mathrm{~cm}^{-1}$ gives rate constants in units of day.

2. The second number in the columns in parentheses is the power of ten by which the first number is multiplied.

3. Based on the GC SOLAR programme.

Source: Reference 7. 
Table 3: $L_{\lambda}$ values for latitude $30^{\circ} N^{1,2,3}$ (North America)

\begin{tabular}{|c|c|c|c|c|}
\hline$\lambda$ centre $(\mathrm{nm})$ & Spring & Summer & Fall & Winter \\
\hline 297.5 & $5.73(-5)$ & $1.09(-4)$ & $3.18(-5)$ & $6.78(-6)$ \\
300.0 & $2.50(-4)$ & $4.11(-4)$ & $1.46(-4)$ & $4.23(-5)$ \\
302.5 & $7.65(-4)$ & $1.14(-3)$ & $4.64(-4)$ & $1.71(-4)$ \\
305.0 & $1.79(-3)$ & $2.46(-3)$ & $1.12(-3)$ & $4.95(-4)$ \\
307.5 & $3.43(-3)$ & $4.45(-3)$ & $2.19(-3)$ & $1.11(-3)$ \\
310.0 & $5.64(-3)$ & $7.02(-3)$ & $3.67(-3)$ & $2.04(-3)$ \\
312.5 & $8.27(-3)$ & $1.00(-2)$ & $5.46(-3)$ & $3.26(-3)$ \\
315.0 & $1.12(-2)$ & $1.32(-2)$ & $7.43(-3)$ & $4.69(-3)$ \\
317.5 & $1.41(-2)$ & $1.64(-2)$ & $9.48(-3)$ & $6.21(-3)$ \\
320.0 & $1.70(-2)$ & $1.95(-2)$ & $1.15(-2)$ & $7.76(-3)$ \\
323.1 & $3.04(-2)$ & $3.46(-2)$ & $2.07(-2)$ & $1.43(-2)$ \\
330.0 & $1.05(-1)$ & $1.18(-1)$ & $7.23(-2)$ & $5.17(-2)$ \\
340.0 & $1.33(-1)$ & $1.48(-1)$ & $9.23(-2)$ & $6.75(-2)$ \\
350.0 & $1.47(-1)$ & $1.63(-1)$ & $1.03(-1)$ & $7.65(-2)$ \\
360.0 & $1.62(-1)$ & $1.80(-1)$ & $1.15(-1)$ & $8.60(-2)$ \\
370.0 & $1.73(-1)$ & $1.91(-1)$ & $1.24(-1)$ & $9.31(-2)$ \\
380.0 & $1.84(-1)$ & $2.04(-1)$ & $1.33(-1)$ & $1.01(-1)$ \\
390.0 & $1.74(-1)$ & $1.93(-1)$ & $1.25(-1)$ & $9.39(-2)$ \\
400.0 & $2.50(-1)$ & $2.77(-1)$ & $1.79(-1)$ & $1.35(-1)$ \\
410.0 & $3.29(-1)$ & $3.64(-1)$ & $2.36(-1)$ & $1.79(-1)$ \\
420.0 & $3.38(-1)$ & $3.74(-1)$ & $2.43(-1)$ & $1.84(-1)$ \\
430.0 & $3.26(-1)$ & $3.61(-1)$ & $2.35(-1)$ & $1.78(-1)$ \\
440.0 & $3.86(-1)$ & $4.26(-1)$ & $2.79(-1)$ & $2.12(-1)$ \\
450.0 & $4.34(-1)$ & $4.79(-1)$ & $3.14(-1)$ & $2.39(-1)$ \\
460.0 & $4.39(-1)$ & $4.85(-1)$ & $3.19(-1)$ & $2.42(-1)$ \\
470.0 & $4.54(-1)$ & $5.01(-1)$ & $3.30(-1)$ & $2.51(-1)$ \\
480.0 & $4.65(-1)$ & $5.13(-1)$ & $3.38(-1)$ & $2.58(-1)$ \\
490.0 & $4.40(-1)$ & $4.85(-1)$ & $3.20(-1)$ & $2.44(-1)$ \\
500.0 & $4.49(-1)$ & $4.95(-1)$ & $3.27(-1)$ & $2.50(-1)$ \\
525.0 & 1.18 & 1.31 & $8.67(-1)$ & $6.61(-1)$ \\
550.0 & 1.23 & 1.36 & $9.03(-1)$ & $6.87(-1)$ \\
575.0 & 1.24 & 1.37 & $9.11(-1)$ & $6.93(-1)$ \\
600.0 & 1.25 & 1.38 & $9.24(-1)$ & $7.04(-1)$ \\
625.0 & 1.26 & 1.39 & $9.34(-1)$ & $7.15(-1)$ \\
650.0 & 1.27 & 1.40 & $9.45(-1)$ & $7.27(-1)$ \\
675.0 & 1.28 & 1.40 & $9.48(-1)$ & $7.32(-1)$ \\
700.0 & 1.27 & 1.39 & 1.82 & $7.31(-1)$ \\
750.0 & 2.44 & 2.67 & 1.41 \\
800.0 & 2.34 & 2.57 & 1.37 \\
\hline
\end{tabular}

Notes:

1. Units of $L_{\lambda}$ are $10^{-3}$ einsteins $\mathrm{cm}^{-2}$ day ${ }^{-1}$. Multiplication of $L_{\lambda}$ by $\varepsilon_{\lambda}$ in units of molar-1 $^{-1} \mathrm{~cm}^{-1}$ gives rate constants in units of day.

2. The second number in the columns in parentheses is the power of ten by which the first number is multiplied.

3. Based on the GC SOLAR programme.

Source: Reference 7. 
Table 4: $L_{\lambda}$ values for latitude $40^{\circ} \mathbf{N}^{1,2,3}$ (North America)

\begin{tabular}{|c|c|c|c|c|}
\hline$\lambda$ centre $(\mathrm{nm})$ & Spring & Summer & Fall & Winter \\
\hline 297.5 & $1.85(-5)$ & $6.17(-5)$ & $7.83(-6)$ & $5.49(-7)$ \\
300.0 & $1.06(-4)$ & $2.70(-4)$ & $4.76(-5)$ & $5.13(-6)$ \\
302.5 & $3.99(-4)$ & $8.30(-4)$ & $1.89(-4)$ & $3.02(-5)$ \\
305.0 & $1.09(-3)$ & $1.95(-3)$ & $5.40(-4)$ & $1.19(-4)$ \\
307.5 & $2.34(-3)$ & $3.74(-3)$ & $1.19(-3)$ & $3.38(-4)$ \\
310.0 & $4.17(-3)$ & $6.17(-3)$ & $2.19(-3)$ & $7.53(-4)$ \\
312.5 & $6.51(-3)$ & $9.07(-3)$ & $3.47(-3)$ & $1.39(-3)$ \\
315.0 & $9.18(-2)$ & $1.22(-2)$ & $4.97(-3)$ & $2.22(-3)$ \\
317.5 & $1.20(-2)$ & $1.55(-2)$ & $6.57(-3)$ & $3.19(-3)$ \\
320.0 & $1.48(-2)$ & $1.87(-2)$ & $8.18(-3)$ & $4.23(-3)$ \\
323.1 & $2.71(-2)$ & $3.35(-2)$ & $1.51(-2)$ & $8.25(-3)$ \\
330.0 & $9.59(-2)$ & $1.16(-1)$ & $5.44(-2)$ & $3.16(-2)$ \\
340.0 & $1.23(-1)$ & $1.46(-1)$ & $7.09(-2)$ & $4.31(-2)$ \\
350.0 & $1.37(-1)$ & $1.62(-1)$ & $8.04(-2)$ & $4.98(-2)$ \\
360.0 & $1.52(-1)$ & $1.79(-1)$ & $9.02(-2)$ & $5.68(-2)$ \\
370.0 & $1.63(-1)$ & $1.91(-1)$ & $9.77(-2)$ & $6.22(-2)$ \\
380.0 & $1.74(-1)$ & $2.04(-1)$ & $1.05(-1)$ & $6.78(-2)$ \\
390.0 & $1.64(-1)$ & $1.93(-1)$ & $9.86(-2)$ & $6.33(-2)$ \\
400.0 & $2.36(-1)$ & $2.76(-1)$ & $1.42(-1)$ & $9.11(-2)$ \\
410.0 & $3.10(-1)$ & $3.64(-1)$ & $1.87(-1)$ & $1.20(-1)$ \\
420.0 & $3.19(-1)$ & $3.74(-1)$ & $1.93(-1)$ & $1.24(-1)$ \\
430.0 & $3.08(-1)$ & $3.61(-1)$ & $1.87(-1)$ & $1.20(-1)$ \\
440.0 & $3.65(-1)$ & $4.26(-1)$ & $2.22(-1)$ & $1.43(-1)$ \\
450.0 & $4.11(-1)$ & $4.80(-1)$ & $2.51(-1)$ & $1.61(-1)$ \\
460.0 & $4.16(-1)$ & $4.85(-1)$ & $2.54(-1)$ & $1.64(-1)$ \\
470.0 & $4.30(-1)$ & $5.02(-1)$ & $2.63(-1)$ & $1.69(-1)$ \\
480.0 & $4.40(-1)$ & $5.14(-1)$ & $2.70(-1)$ & $1.74(-1)$ \\
490.0 & $4.16(-1)$ & $4.86(-1)$ & $2.56(-1)$ & $1.65(-1)$ \\
500.0 & $4.25(-1)$ & $4.96(-1)$ & $2.62(-1)$ & $1.68(-1)$ \\
525.0 & 1.12 & 1.31 & $6.93(-1)$ & $4.45(-1)$ \\
550.0 & 1.16 & 1.36 & $7.21(-1)$ & $4.61(-1)$ \\
575.0 & 1.17 & 1.37 & $7.22(-1)$ & $4.61(-1)$ \\
600.0 & 1.18 & 1.38 & $7.39(-1)$ & $4.69(-1)$ \\
625.0 & 1.20 & 1.40 & $7.50(-1)$ & $4.82(-1)$ \\
650.0 & 1.21 & 1.41 & $7.62(-1)$ & $4.95(-1)$ \\
675.0 & 1.22 & 1.41 & $7.66(-1)$ & $5.03(-1)$ \\
700.0 & 1.21 & 1.40 & 1.48 & $5.05(-1)$ \\
750.0 & 2.33 & 2.69 & $9.84(-1)$ \\
800.0 & 2.25 & 2.59 & $9.56(-1)$ \\
\hline
\end{tabular}

Notes:

1. Units of $L_{\lambda}$ are $10^{-3}$ einsteins $\mathrm{cm}^{-2}$ day ${ }^{-1}$. Multiplication of $L_{\lambda}$ by $\varepsilon_{\lambda}$ in units of molar-1 $^{-1} \mathrm{~cm}^{-1}$ gives rate constants in units of day.

2. The second number in the columns in parentheses is the power of ten by which the first number is multiplied.

3. Based on the GC SOLAR programme.

Source: Reference 7. 
TABLE 5. $L_{\lambda}$ values for latitude $50^{\circ} \mathbf{N}^{1,2,3}$ (North America)

\begin{tabular}{|c|c|c|c|c|}
\hline$\lambda$ centre $(\mathrm{nm})$ & Spring & Summer & Fall & Winter \\
\hline 297.5 & $3.61(-6)$ & $2.86(-5)$ & $9.58(-7)$ & $5.47(-8)$ \\
\hline 300.0 & $3.05(-5)$ & $1.50(-4)$ & $8.27(-6)$ & $4.17(-7)$ \\
\hline 302.5 & $1.54(-4)$ & $5.33(-4)$ & $4.47(-5)$ & $2.62(-6)$ \\
\hline 305.0 & $5.24(-4)$ & $1.39(-3)$ & $1.63(-4)$ & $1.34(-5)$ \\
\hline 307.0 & $1.32(-3)$ & $2.89(-3)$ & $4.39(-4)$ & $5.14(-5)$ \\
\hline 310.0 & $2.66(-3)$ & $5.05(-3)$ & $9.32(-4)$ & $1.49(-4)$ \\
\hline 312.5 & $4.53(-3)$ & $7.75(-3)$ & $1.66(-3)$ & $3.43(-4)$ \\
\hline 315.0 & $6.82(-3)$ & $1.08(-2)$ & $2.58(-3)$ & $6.52(-4)$ \\
\hline 317.5 & $9.34(-3)$ & $1.40(-2)$ & 3.64(-3) & $1.07(-3)$ \\
\hline 320.0 & $1.19(-2)$ & $1.71(-2)$ & $4.76(-3)$ & $1.57(-3)$ \\
\hline 323.1 & $2.25(-2)$ & $3.12(-2)$ & $9.19(-3)$ & $3.39(-3)$ \\
\hline 330.0 & $8.26(-2)$ & $1.10(-1)$ & $3.48(-2)$ & $1.45(-2)$ \\
\hline 340.0 & $1.09(-1)$ & $1.40(-1)$ & $4.71(-2)$ & $2.12(-2)$ \\
\hline 350.0 & $1.22(-2)$ & $1.57(-1)$ & $5.43(-2)$ & $2.53(-2)$ \\
\hline 360.0 & $1.36(-1)$ & $1.74(-1)$ & $6.18(-2)$ & $2.96(-2)$ \\
\hline 370.0 & $1.47(-1)$ & $1.86(-1)$ & $6.76(-2)$ & $3.30(-2)$ \\
\hline 380.0 & $1.57(-1)$ & $1.99(-1)$ & 7.37(-2) & $3.65(-2)$ \\
\hline 390.0 & $1.48(-1)$ & $1.87(-1)$ & $6.89(-2)$ & $3.49(-2)$ \\
\hline 400.0 & $2.12(-1)$ & $2.69(-1)$ & $9.90(-2)$ & $4.98(-2)$ \\
\hline 410.0 & $2.80(-1)$ & $3.55(-1)$ & $1.31(-1)$ & $6.54(-2)$ \\
\hline 420.0 & $2.89(-1)$ & $3.65(-1)$ & $1.35(-1)$ & $6.71(-2)$ \\
\hline 430.0 & $2.79(-1)$ & $3.52(-1)$ & $1.31(-1)$ & $6.47(-2)$ \\
\hline 440.0 & $3.31(-1)$ & $4.17(-1)$ & $1.55(-1)$ & $7.66(-2)$ \\
\hline 450.0 & $3.73(-1)$ & $4.69(-1)$ & $1.75(-1)$ & $8.62(-2)$ \\
\hline 460.0 & $3.78(-1)$ & $4.75(-1)$ & $1.78(-1)$ & $8.74(-2)$ \\
\hline 470.0 & $3.90(-1)$ & $4.91(-1)$ & $1.84(-1)$ & $8.95(-2)$ \\
\hline 480.0 & $4.00(-1)$ & $5.03(-1)$ & $1.89(-1)$ & $9.15(-2)$ \\
\hline 490.0 & $3.78(-1)$ & $4.76(-1)$ & $1.79(-1)$ & $8.62(-2)$ \\
\hline 500.0 & $3.86(-1)$ & $4.85(-1)$ & $1.83(-1)$ & $8.77(-2)$ \\
\hline 525.0 & 1.01 & 1.28 & $4.84(-1)$ & $2.28(-1)$ \\
\hline 550.0 & 1.05 & 1.33 & $5.03(-1)$ & $2.32(-1)$ \\
\hline 575.0 & 1.05 & 1.34 & $5.04(-1)$ & $2.28(-1)$ \\
\hline 600.0 & 1.06 & 1.35 & $5.13(-1)$ & $2.32(-1)$ \\
\hline 625.0 & 1.08 & 1.37 & $5.26(-1)$ & $2.42(-1)$ \\
\hline 650.0 & 1.10 & 1.38 & $5.39(-1)$ & $2.53(-1)$ \\
\hline 675.0 & 1.11 & 1.39 & $5.47(-1)$ & $2.61(-1)$ \\
\hline 700.0 & 1.11 & 1.38 & $5.49(-1)$ & $2.66(-1)$ \\
\hline 750.0 & 2.15 & 2.66 & 2.07 & $5.22(-1)$ \\
\hline 800.0 & 2.08 & 2.57 & 1.04 & $5.11(-1)$ \\
\hline
\end{tabular}

Notes:

1. Units of $L_{\lambda}$ are $10^{-3}$ einsteins $\mathrm{cm}^{-2}$ day ${ }^{-1}$. Multiplication of $L_{\lambda}$ by $\varepsilon_{\lambda}$ in units of molar-1 $^{-1} \mathrm{~cm}^{-1}$ gives rate constants in units of day.

2. The second number in the columns in parentheses is the power of ten by which the first number is multiplied.

3. Based on the GC SOLAR programme.

Source: Reference 7. 